\title{
ASSENTAMENTO RURAL E AGRICULTURA FAMILIAR: UM DESENVOLVIMENTO PAUTADO NAS POLÍTICAS PÚBLICAS
}

\author{
Ana Cláudia Soares da SILVA ${ }^{1}$ \\ Ana Ivania Alves FONSECA ${ }^{2}$
}

\section{Resumo}

A agricultura familiar é uma fonte de geração de renda para trabalhadores rurais dos assentamentos da região Norte de Minas. Com a criação do Programa Nacional de Fortalecimento da Agricultura Familiar - PRONAF houve a integração de uma política pública específica para o desenvolvimento dos agricultores familiares, o que trouxe no âmbito regional avanços, perspectivas econômicas, geração de renda e sustento para as famílias. Este trabalho busca analisar como o PRONAF tem contribuído para o desenvolvimento do assentamento Fazenda Serrador, localizado no município de Francisco Sá - MG. O caminho metodológico baseou-se em estudo bibliográfico em diversos autores que discutem a temática, trabalho de campo, entrevistas e registros fotográficos. Assim, se faz necessário ressaltar a importância da agricultura familiar que vem ganhado espaço a partir da implantação de políticas públicas de incentivo para o homem do campo e para o desenvolvimento rural.

Palavras-chave: Agricultura Familiar. PRONAF. Assentamentos Rurais.

\section{Abstract}

\section{Rural settlement and family agriculture: a development in public policies}

Family farming is a source of income for rural workers in the settlements of the North of Minas Gerais. With the creation of the National Program for the Strengthening of Family Agriculture - PRONAF, a specific public policy was introduced for the development of family farmers, which brought progress, economic prospects, income generation and livelihoods in the region. This work seeks to analyze how PRONAF has contributed to the development of Fazenda Serrador settlement located in the municipality of Francisco Sá - MG. The methodological path was based on a bibliographical study, in several authors that discuss the theme, field work, interviews and photographic records. Thus, it is necessary to emphasize the importance of family farming that has gained space from the implementation of public policies to encourage rural man and rural development.

Key words: Family Agriculture. PRONAF. Rural Settlements.

\footnotetext{
1 Mestranda em Geografia pela Universidade Estadual de Montes Claros/ Unimontes. E-mail: anaclaudia.univ@yahoo.com.br

2 Professora do Departamento de Geociências/Unimontes. E-mail: anaivania@gmail.com
} 


\section{INTRODUÇÃO}

O Assentamento Fazenda Serrador foi criado em 1999, constituído pelo Programa Cédula da Terra, atual Programa Nacional de Crédito Fundiário - PNCF. O assentamento localiza-se às margens da BR 251, a 6 (seis) km de Francisco Sá na região do Norte de Minas, com o perímetro $8.479,70 \mathrm{~m}$ e com uma área total de 386,71ha (Figura 1) (ASSOCIAÇÃO DOS TRABALHADORES RURAIS SEM TERRA DE FRANCISCO SÁ, 2015).
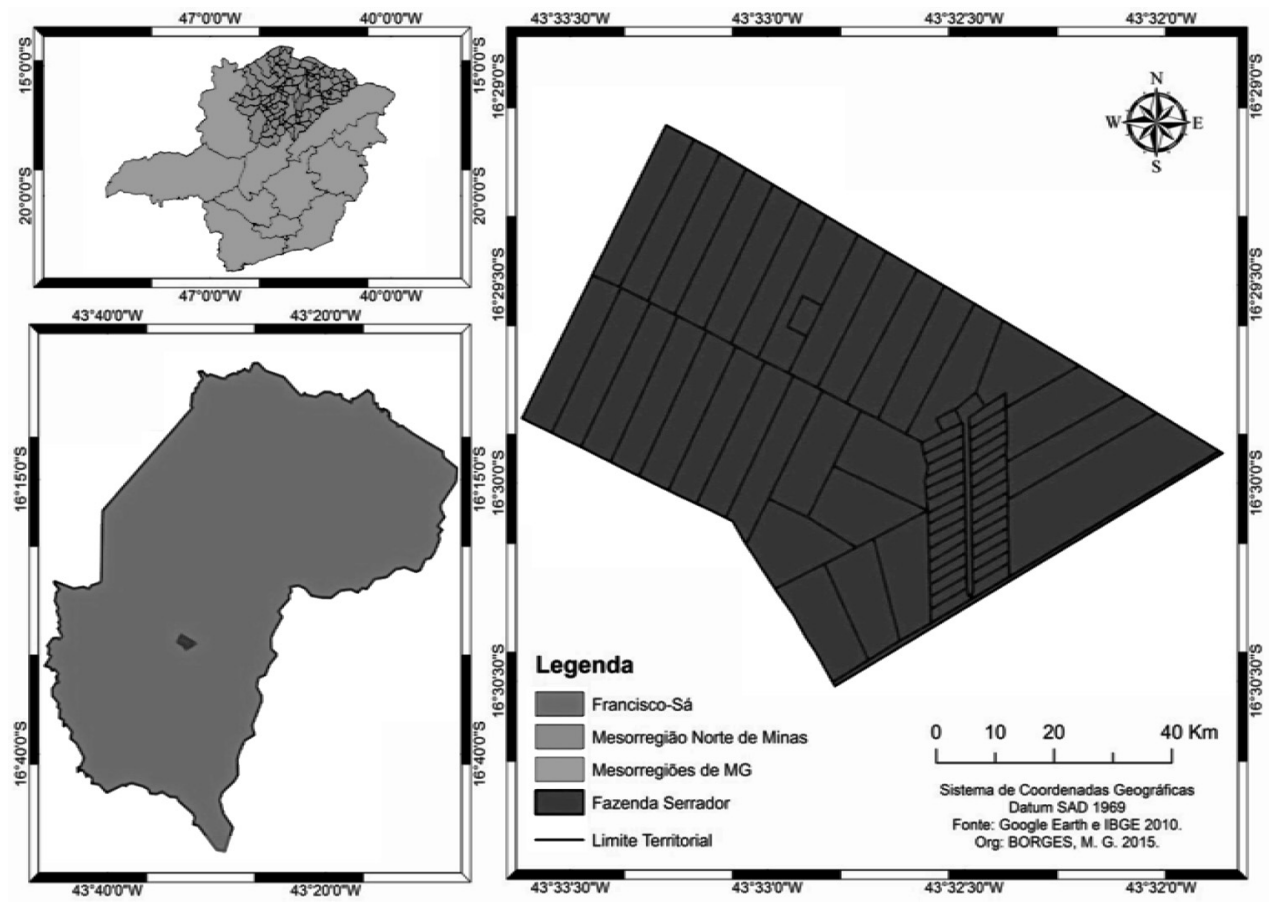

\section{Figura 1 - Localização do Assentamento Fazenda Serrador- MG \\ Org.: BORGES, 2015.}

Para efeitos de caracterização, conforme o Instituto Brasileiro de Geografia e Estatística - IBGE (2010), o município de Francisco Sá apresenta 2.747,3km² de extensão territorial com uma população de aproximadamente 24.912 hab., sendo 10.015 hab. nas áreas rurais e 14.897hab. nas áreas urbanas e está situado a $50 \mathrm{~km}$ a Norte-Leste da cidade de Montes Claros.

O Norte de Minas individualiza-se por apresentar características marcantes, tanto do ponto de vista físico quanto do ponto de vista socioeconômico, essa região marca a transição do bioma cerrado de clima tropical semiúmido e o bioma caatinga de clima semiárido. Embora o Norte de Minas esteja inserido em uma região de destaque econômico do país, grande parte dos municípios apresenta baixo Índice de Desenvolvimento Humano Municipal (IDHM) (PEREIRA, 2006). É relevante discutir sobre o papel do Estado em consonância às políticas de desenvolvimento implantadas na região, principalmente, nos assentamentos rurais. 
Os assentamentos no Brasil, especificamente na mesorregião Norte de Minas, têm pautado sua produção na chamada agricultura familiar. Desde o início do processo de ocupação do território brasileiro a agricultura familiar já fazia parte das atividades produtivas do país. Contudo, "[...] a expressão "agricultura familiar" é de uso recente no vocabulário científico, governamental e das políticas públicas, no Brasil [...]" (Abramovay; Piketty, 2005, p. 57). De acordo com Picolotto (2014) a categoria agricultura familiar e a difusão política para essa classe tem apresentado resultados expressivos somente a partir da década de 1990. A ação do Estado contribuiu para definição do sentido oficial dessa categoria em consonância as políticas públicas para o reconhecimento e fortalecimento da agricultura familiar.

A prática da agricultura familiar nos assentamentos rurais teve como primeiro incentivo o Programa de Crédito Especial para a Reforma Agrária - PROCERA criado em 1985 pelo Conselho Monetário Nacional que buscou promover a melhoria e aumento da produção agrícola. Na década de 1990 o PROCERA foi ampliado e substituído pelo Programa Nacional de Fortalecimento da Agricultura Familiar - PRONAF que trouxe ampliação nas linhas de financiamentos e condições específicas para cada modalidade e público diferenciado (Rezende, 1999).

É objetivo deste trabalho, analisar como o Programa Nacional de Fortalecimento da Agricultura Familiar - PRONAF tem contribuído para o desenvolvimento do Assentamento Fazenda Serrador localizado no município de Francisco Sá - MG. O caminho metodológico constituiu em levantamento bibliográfico para fundamentação da parte teórica, trabalho de campo, entrevistas e registros fotográficos.

\section{AS TRANSFORMAÇÕES DO ESPAÇO RURAL ATRAVÉS DOS ASSENTAMENTOS}

Nos últimos anos, os estudos sobre assentamentos têm ocupado espaço de pesquisas e debates no meio acadêmico, para tanto repensar o conceito de espaço rural e os contrastes evidenciados leva em consideração uma série de fatores e elementos. O movimento dos trabalhadores rurais têm sido responsável por constantes dinâmicas na organização e reestruturação do espaço rural brasileiro.

O espaço rural é dinâmico e apresenta constantes transformações. De acordo com Schneider (2010) quatro fatores são importantes para este desenvolvimento. O primeiro está relacionado com a trajetória das discussões em torno da agricultura familiar, com destaque para o potencial produtivo, social e econômico. O segundo refere-se a crescente influência do Estado, através de políticas de apoio a agricultura familiar e ações relacionadas à reforma agrária, segurança alimentar, entre outras. 0 terceiro gira em torno das mudanças no âmbito político e ideológico no espaço rural com a presença do universo da agricultura familiar cercada pelas elites agrárias e o quarto fator está relacionado com o desenvolvimento rural com o tema da sustentabilidade ambiental.

A definição de assentamentos diz respeito à instalação de novas propriedades agrícolas, como resultado de ação das políticas públicas. O termo assentamento, introduzido pelos órgãos oficiais, dá ideia de alocação, de fixação dos trabalhadores na agricultura, daí o surgimento de uma nova categoria no espaço rural, o "assentado" que são aqueles que vivem em um assentamento. Esta terminologia desmistifica ou tenta ocultar um ato anterior aos trabalhadores que lutaram com bravura pelo direito e acesso a terra (FURTADO, 2000). 
Nessa conjuntura de lutas, os assentamentos rurais são observados como uma nova configuração de formas sociais integradas ao processo social e político. A redistribuição fundiária propiciou o acesso à terra aos trabalhadores que até então não obtinham um pedaço de terra para morar e trabalhar, permitindo a estes camponeses o acesso a linhas de créditos para produção e independência financeira. CarvaIho (1998) destaca que:

[...] os assentamentos, compreendem um conjunto de famílias de trabalhadores rurais vivendo e produzindo num determinado imóvel rural, desapropriado ou adquirido pelo governo federal (no caso de aquisição, também, pelos governos estaduais) com o fim de cumprir as disposições constitucionais e legais relativas à reforma agrária. A expressão assentamento é utilizada para identificar não apenas uma área de terra, no âmbito dos processos de reforma agrária, destinada à produção agropecuária e ou extrativista, mas, também, um agregado heterogêneo de grupos sociais constituídos por famílias de trabalhadores rurais (CARVALHO, 1998 , p. 4).

A presença de assentamentos enquanto territórios independentes se configuram como novos espaços para implantação de políticas públicas, dessa maneira a condição de assentado possibilitou, a tomada de empréstimos para produção, contribuindo de maneira significativa para sanar as dificuldades econômicas no campo.

Para compreensão do paradoxo da reforma agrária no país, é necessário considerar a heterogeneidade dos movimentos e as disputas territoriais que se formaram nos últimos anos. Há que se pontuar que houve na dinâmica da luta pela terra, diferentes momentos e conceitos, que foram representativos para a atual evolução do processo agrário, como os movimentos de ocupações, acampamentos e assentamentos.

As ocupações dão origem aos acampamentos que são formas de mobilização extensiva do Movimento dos Trabalhadores Rurais Sem-Terra (MST). Os acampamentos são um importante instrumento de estratégia de luta pela terra, que fazem referência a um aglomerado "de barracos de lona". Já os assentamentos, correspondem à conquista da terra através da organização e luta social do camponês sem terra. Esse foco é a principal resposta do Estado à pressão exercida pelos movimentos sociais demandantes por uma reforma agrária (CALDART, 2004).

A reforma agrária é entendida como uma política pública que procura reorganizar a estrutura fundiária do país, através de um conjunto de medidas, disposto no Estatuto da Terra, Lei no 4.504/64. Esse marco legal regulamenta os direitos e modificações do regime de posse e uso da terra, com fins de promover adequadamente a função social. A política pública de reforma agrária abrange uma amplitude de programas e diferentes modalidades de assentamentos (INCRA, 2017).

Atualmente os conjuntos de políticas, programas e ações governamentais destinados especificamente aos agricultores familiares de todo o país vem apresentando resultados extremamente positivos em termos de produção. As transformações do espaço rural a partir dos assentamentos são evidenciadas pelas dinâmicas territoriais que modificaram as paisagens, as relações sociais, econômicas, culturais e ambientais, fatores estes, que alteram constantemente o espaço rural. 


\section{AGRICULTURA FAMILIAR E O PRONAF NO ASSENTAMENTO FAZENDA SERRADOR}

A propriedade familiar no inciso II, do art. 40, do Estatuto da Terra, é definida como aquela propriedade que, explora direta e pessoalmente o imóvel rural com o trabalho familiar, e em certos casos, eventualmente, com a ajuda de terceiros, propondo-Ihes o sustento, progresso social e econômico (BRASIL, 1964). As reivindicações por políticas específicas para a agricultura familiar ganharam evidências somente durante a Assembleia Nacional Constituinte em 1987, com a elaboração de uma proposta de lei agrícola pelas entidades representativas, a qual incluía políticas de créditos voltadas para a agricultura familiar (SILVA, 1999).

As políticas públicas para a área rural, em especial a política agrícola, durante 1960 e 1970, período de modernização da agricultura, favoreciam aos monocultores e latifundiários, desfavorecendo o setor do pequeno agricultor familiar e as famílias assentadas. As contradições no ambiente agrário, entre o latifúndio e o pequeno produtor, tiveram início com as Ligas Camponesas e os movimentos de luta pela reforma agrária, que foram aniquilados na década de 1964, pelo regime militar, fator que impediu o desenvolvimento da agricultura familiar como atividade intensiva e permanente. Entretanto, a agricultura familiar, ainda se encontra com certas dificuldades no que tange o desenvolvimento tecnológico e mercado agrícola (ALBUQUERQUE et al, 2004).

Em 1985 foi criado o PROCERA como a primeira política agrícola para os assentamentos da reforma agrária com custeio para a lavoura e investimentos para estruturação dos lotes. Em 1996 foi constituído o PRONAF, elaborado pelo Decreto no 1.946/96, a partir de então as famílias assentadas passou a ter acesso a uma política de créditos específica sobre os critérios do PRONAF "A" (RESENDE, 1999).

A agricultura familiar foi caracterizada e definida pela Lei no 11.326 de 24 de julho de 2006 (BRASIL, 2006). As políticas públicas para a agricultura familiar, enquanto estratégias para o desenvolvimento rural apresentaram evolução a partir da linha de crédito do PRONAF, elegendo novas transformações para a agricultura familiar e para os assentamentos, fator que movimentou o cenário de produção e pluriatividade no meio rural (ALENTEJANO, 1977).

O PRONAF apresenta grupos diferenciados de enquadramento de créditos. As conceituações desses grupos são adotadas por encargos financeiros próprios e individualizadas para cada modalidade. No caso específico do "grupo A" são destinados aos agricultores familiares de assentamentos, seja pelo Programa Nacional de Reforma Agrária - PNRA ou pelo Programa Nacional Crédito Fundiário - PNCF. Têm se-consolidado no âmbito do desenvolvimento rural, na perspectiva de geração econômica no campo, o que permitiu a estruturação inicial dos lotes e desenvolvimento da produção local.

O PRONAF "A" foi o fomento inicial necessário para instalação das famílias no assentamento Fazenda Serrador. Após divisão do terreno e a construção das casas, os lotes foram entregues às famílias, onde foi incumbida a pagar pela terra no valor de $160.000,00$ (dividido pelas 30 famílias) com três anos de carência e com o término de pagamento em 2020.

As trinta casas do assentamento foram construídas pelos próprios assentados. A organização foi realizada pelo esquema de mutirões, seguindo um modelo de 
agrovilas $^{3}$. Ao término, as casas foram sorteadas pelos selecionados do programa, nessa divisão, as casas e os quintais contabilizaram 1 hectare e os terrenos com 10.7 hectares para agricultura e pecuária. Os trabalhadores rurais vieram morar na propriedade, utilizando o terreno para o sustento com mão de obra familiar. A primeira linha de crédito do PRONAF foi ao valor de $12.000,00$ com carência de três anos e rebates anuais. Essa política foi o primeiro passo para o desenvolvido do assentamento, como também outros créditos e garantias safras ${ }^{4}$. 0 recurso do financiamento foi aplicado na pecuária, na agricultura e outras atividades.

De acordo com Guanziroli et al (2001, p. 35) [...]"quando são implementadas políticas agrícolas de apoio a produção familiar, torna-se disponível o crédito de custeio e/ou investimento (como no caso do PRONAF), e acelera este processo de consolidação dos sistemas produtivos e demais atividades [...]"viabilizando uma inserção rentável no mercado econômico com a prática muitas vezes da agricultura orgânica na produção.

A agricultura familiar no assentamento Fazenda Serrador é exercida por atividades diversificadas e de características agroecológicas, nesses cultivos, a produção é mantida tanto pelo sistema de irrigação ou pelo sistema de sequeiro, plantação por período sazonal, nas épocas de chuva. Nesse contexto, Guanziroli et al $(2001$, p. 250) destaca que "é preciso ter claro que uma verdadeira reforma agrária tem como objetivos estratégicos elevar a agricultura familiar à posição de protagonista do processo de geração e distribuição de riqueza no meio rural".

A agricultura familiar é heterogênea, seja pela diversidade regional, ou pela capacidade de produção. O desenvolvimento fundamentado na reforma agrária e na agricultura familiar deve-se conjugar a associação do equilíbrio e a produção ecológica adaptada ao uso racional dos recursos naturais. Desse modo, Altieri (1996) aponta que a verdadeira sustentabilidade será obtida somente quando os camponeses incrementarem a terra, recursos e tecnologias adequadas, assegurando o controle dos recursos naturais.

Fonseca (2012) salienta que:

O modo de produção enquadra-se perfeitamente nos princípios agroecológicos; mas este fazer perpassa pela relação homem/natureza, compondo, assim, um conjunto multifuncional da agricultura familiar; com destaque, neste estudo, para as funções sociais, ambientais, econômicas e culturais, ensejando, assim, estratégias de territorialidade, cuja reprodução está ancorada na manutenção dos quintais ecológicos (FONSECA, 2012, p.111).

Conforme a autora, a cultura multifuncional é destaque da agricultura familiar desempenhada pela interação homem/meio. Nesta perceptiva, um bom exemplo são os quintais dos lotes do assentamento Fazenda Serrador, que são organizados produ-

\footnotetext{
${ }^{3}$ Agrovila: núcleo habitacional e produtivo construído geralmente em áreas rurais para o desenvolvimento da agricultura e destinado a receber populações que estão sendo deslocadas de outras áreas por razões climáticas ou devido à construção de obras públicas como, por exemplo, barragens que servem como reservatórios para a produção de energia elétrica (SANDRONI, 1999, p. 18).

4 O Programa Garantia-Safra, ação do PRONAF foi criado para operar nas regiões de atuação da Superintendência do Desenvolvimento do Nordeste (SUDENE), o objetivo foi acompanhar os agricultores familiares que sofrem com a perda da safra, seja pela seca ou pelo excesso de chuva. A formação do fundo cobrirá os eventuais prejuízos, a adesão é realizada pelo governo federal, estadual e municipal, mediante a quitação deum taxa paga anualmente pelo agricultor (BRASIL, 2011).
} 
tivamente pela sistematização de diversos cultivos, ou seja, são incorporados arranjos de várias espécies agrícolas e/ou animais no mesmo espaço. Essa dinâmica cultural, produzida pelos agricultores familiares é potencialmente significativa para o sustento familiar e geração de renda. As (Figuras 2 e 3) mostram os plantios nos lotes do assentamento.

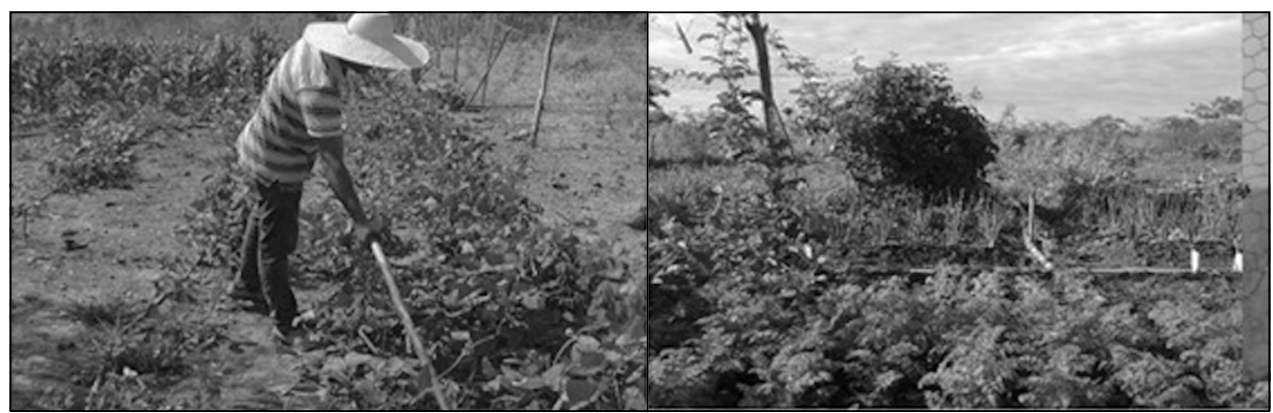

Figura 2 - Plantio de milho e feijão

Fonte: SILVA; 2016.
Figura 3 - Hortaliça

Fonte: SILVA; 2016.

Os quintais constituem uma fonte de agregação de renda, segurança alimentar, geração econômica e preservação ecológica. Esses espaços marcam a atuação do trabalho familiar, que cultivam a produção de hortaliças, temperos e plantas medicinais. Entretanto, é válido ressaltar que a base de sustentação dessas famílias não se fundamenta somente na agricultura familiar devido aos vários problemas na produção e renda no campo, a aposentaria rural é um fator relativamente autêntico para essas famílias.

O assentamento Fazenda Serrador, assim como os demais na região Norte de Minas são ancorados por uma produção pautada em estratégia de convivência com a seca e prolongada estiagem. Em evidência, algumas maneiras são tomadas, para a criação e alimentação do gado com a instalação de pequenos silos para sustentar os animais nos períodos de estiagem.

O desenvolvimento da reforma agrária e da agricultura familiar quando integradas as questões ambientais e dos ecossistemas possibilitam uma utilização mais racional dos recursos naturais (SAUER, 1998). O desenvolvimento dos assentamentos na região Norte de Minas com as chamadas políticas públicas destinadas ao cumprimento da reforma agrária, minimizaram os conflitos sociais e contribuíram para geração de renda, uma vez que os lotes tornaram-se espaços produtivos com uma policultura rica e diversificada.

Desta maneira, os assentamentos rurais apresentam territorialidades e propriedades agrícolas distintas, formado por agricultores familiares que se desenvolveram pela adoção de políticas de apoio, como o caso do Pronaf, gerando revalorização para o espaço rural. Os espaços formados através de assentamentos rurais constituem novas formas de socialização e saberes que são acumulados por famílias de diversas culturas, que migram em busca de acesso a terra e nessa trajetória, relações são produzidas. 


\section{CONSIDERAÇÕES FINAIS}

Portanto, as modalidades e os diversos programas de assentamentos representaram uma nova realidade para a questão agrária, correspondente aos inúmeros projetos de assentamentos e territorialidades distintas. Desse modo, a atualidade da reforma agrária brasileira não pode ser interpretada sem levar em conta a diversidade dos territórios dos assentamentos e da identidade dos camponeses assentados.

Com a implantação do PRONAF o assentamento Fazenda Serrador Apresentou grandes avanços, com diversificação da produção e geração de renda. A agricultura familiar tem pautado nas estratégias sustentáveis, incluindo as questões ambientais e paisagens ecológicas. A chamada sustentabilidade está relacionada à conservação dos recursos naturais, ressaltando a importância da preservação dos bens naturais, bem como a aplicação racional nos usos do solo no dia a dia, trazendo menos impactos ao meio ambiente rural.

\section{REFERÊNCIAS}

ABRAMOVAY, Ricardo; PIKETTY, Marie-Gabrielle. Política de crédito do Programa Nacional de Fortalecimento da Agricultura Familiar (Pronaf): resultados e limites da experiência brasileira nos anos 90. Cadernos de Ciência \& Tecnologia, Brasília, v. 22, n. 1, p. 53-66, jan./abr. 2005.

ALBUQUERQUE, Francisco José Batista de et al. As políticas públicas e os projetos de assentamento. Estudos de Psicologia 2004, p. 81-88.

ALENTEJANO, Paulo Roberto Raposo. Reforma agrária e pluriatividade no Rio de Janeiro: repensando a dicotomia rural-urbana nos assentamentos rurais. 199 p. Dissertação (Mestrado) - CPDA/URFJ, Rio de Janeiro, 1977.ALTIERI, Miguel A. Una perspectiva agroecológica para orientar los programas de educación de postgrado en Economía Agrícola y Desarrollo Rural en la América Latina del siglo XXI. In: La postgraduacióneneconomía y políticas agrícolas ydes a rrollo rural: curricula y perfil profesional. Rio de Janeiro: Editora REDCAPA/EDUR, 1996.

BRASIL. IBGE. Agricultura familiar primeiros resultados: Brasil grandes regiões e unidades da federação. Censo Agropec. Rio de Janeiro, p.1-267, 2006.

IBGE. Cidades, 2010. Disponível em< http://cidades.ibge.gov.br/xtras/ perfil.php lang $=\&$ codmun $=312670 \&$ search $=$ minasgerais $\mid$ francisco-sa $>$. Acesso 04/ 2017.

INCRA Reforma agrária. Disponível em<http://www.incra.gov.br/ reforma_agraria>acesso 05/2017.

. Lei no 4.504, de 30 de novembro de 1964 - Planalto. Estatuto da Terra Disponível em <http://www.planalto.gov.br/ccivil_03/leis/L4504.htm/> Acesso em 07/ 2017.

Cartilha de acesso ao PRONAF: saiba como obter crédito para a agricultura familiar. Brasília, DF. 2011.p.32.

Lei no 11.326, de 24 de Julho de 2006. Política Nacional da Agricultura Familiar e Empreendimentos Familiares Rurais. Disponível em < http://www.planalto.gov.br/ ccivil_03/_ato2004-2006/2006/lei/l11326.htm> Acesso em 07/2017. 
CALDART, Roseli Salete. Pedagogia do Movimento Sem Terra. São Paulo: Expressão Popular, 2004.

CARVALHO, Horácio Martins de. Formas de associativismo vivenciadas pelos trabalhadores rurais nas áreas oficiais de reforma agrária no Brasil. In: Ministério Extraordinário de Política Fundiária e Instituto Interamericano de Cooperação para a Agricultura. Curitiba: Agosto, 1998.

FONSECA, Ana Ivania Alves. Agricultura Familiar como Sustentabilidade: Estudo de Caso do Planalto Rural de Montes Claros/MG. 2012.181 f. Tese de Doutorado em Geografia. Instituto de Geociências e Ciências Exatas -Universidade Estadual Paulista Júlio de Mesquita Filho, Rio Claro. 2012.p.111.

FURTADO, Ribamar. A intervenção participativa dos atores (INPA) - uma metodologia de capacitação para o desenvolvimento local sustentável. Brasília: Instituto Interamericano de Cooperação para a Agricultura (IICA), 2000. p. 180.

GUANZIROLI, Carlos Enrique et al. Agricultura familiar e reforma agrária XXI.Rio de Janeiro: Garamond, 2001. 288p.

LANDAU, Elena Charlotte et al. Variação geográfica do tamanho dos módulos fiscais no Brasil. Sete Lagoas: Documentos/ Embrapa Milho e Sorgo, 2012. 199 p. ASSOCIAÇÃO DOS TRABALHADORES RURAIS SEM TERRA DE FRANCISCO SÁ. Levantamento topográfico da área. Acervo da Associação, Fazenda Serrador, 2015.

PEREIRA, Anete Marília. Múltiplos Olhares sobre a Região Norte de Minas. In: Revista Cerrados, v. 4, n. 1. Montes Claros: Ed. Unimontes. 2006.

PICOLOTTO, Everton Lazzaretti. Os atores da construção da categoria agricultura familiar no Brasil. Rev. Econ. Sociol. Rural, vol. 52, supl.1 Brasília, 2014.

REZENDE, Gervásio Castro de. Programa de Crédito Especial para Reforma Agrária (Procera): institucionalidade, subsídio e eficácia. Texto para discussão. n. 648. Rio de Janeiro, 1999.

SANDRONI, Paulo. Novíssimo Dicionário de Economia. São Paulo: Best Seller, 1999.

SAUER, Sérgio. Reforma agrária e geração de empregos no meio rural. São Paulo: ABET, 1998.

SCHNEIDER, Sérgio. Situando o desenvolvimento rural no Brasil: o contexto e as questões em debate. Revista de Economia Política, vol. 30 n.3 São Paulo. Jul /Set. 2010.

SILVA, Enid Rocha Andrade. Programa Nacional de Fortalecimento da Agricultura Familiar (PRONAF): Relatório Técnico das Ações Desenvolvidas no Período 1995/1998. Textos para discussão. Brasília, Agosto. n. 664, 1999. 